\title{
O Arco Metropolitano do Rio de Janeiro: modernização, acumulação e novo desenvolvimentismo
}

Arche Métropolitaine de Rio de Janeiro: modernisation, accumulation et nouveau développementalisme

El Arco Metropolitano de Río de Janeiro: modernización, acumulación y nuevo desenvolvimentismo

Metropolitan Arch of Rio de Janeiro: modernization, accumulation and new developmentalism

\section{Victor Tinoco}

\section{(2) OpenEdition}

\section{Journals}

Electronic version

URL: http://journals.openedition.org/espacoeconomia/6136

DOI: $10.4000 /$ espacoeconomia.6136

ISSN: 2317-7837

\section{Publisher}

Núcleo de Pesquisa Espaço \& Economia

Electronic reference

Victor Tinoco, «O Arco Metropolitano do Rio de Janeiro: modernização, acumulação e novo desenvolvimentismo », Espaço e Economia [Online], 14 | 2019, Online since 12 August 2019, connection on 04 September 2019. URL : http://journals.openedition.org/espacoeconomia/6136; DOI : 10.4000/ espacoeconomia.6136

This text was automatically generated on 4 September 2019.

(C) NUPEE 


\section{O Arco Metropolitano do Rio de Janeiro: modernização, acumulação e novo desenvolvimentismo}

Arche Métropolitaine de Rio de Janeiro: modernisation, accumulation et nouveau développementalisme

El Arco Metropolitano de Río de Janeiro: modernización, acumulación y nuevo desenvolvimentismo

Metropolitan Arch of Rio de Janeiro: modernization, accumulation and new developmentalism

Victor Tinoco

\section{Introdução}

O Arco Metropolitano é uma obra infraestrutural que corta a Região Metropolitana do Rio de Janeiro, passando pelos municípios de Itaboraí, Guapimirim, Magé, Duque de Caxias, Nova Iguaçu, Japeri, Seropédica e Itaguaí (Figura 1). 


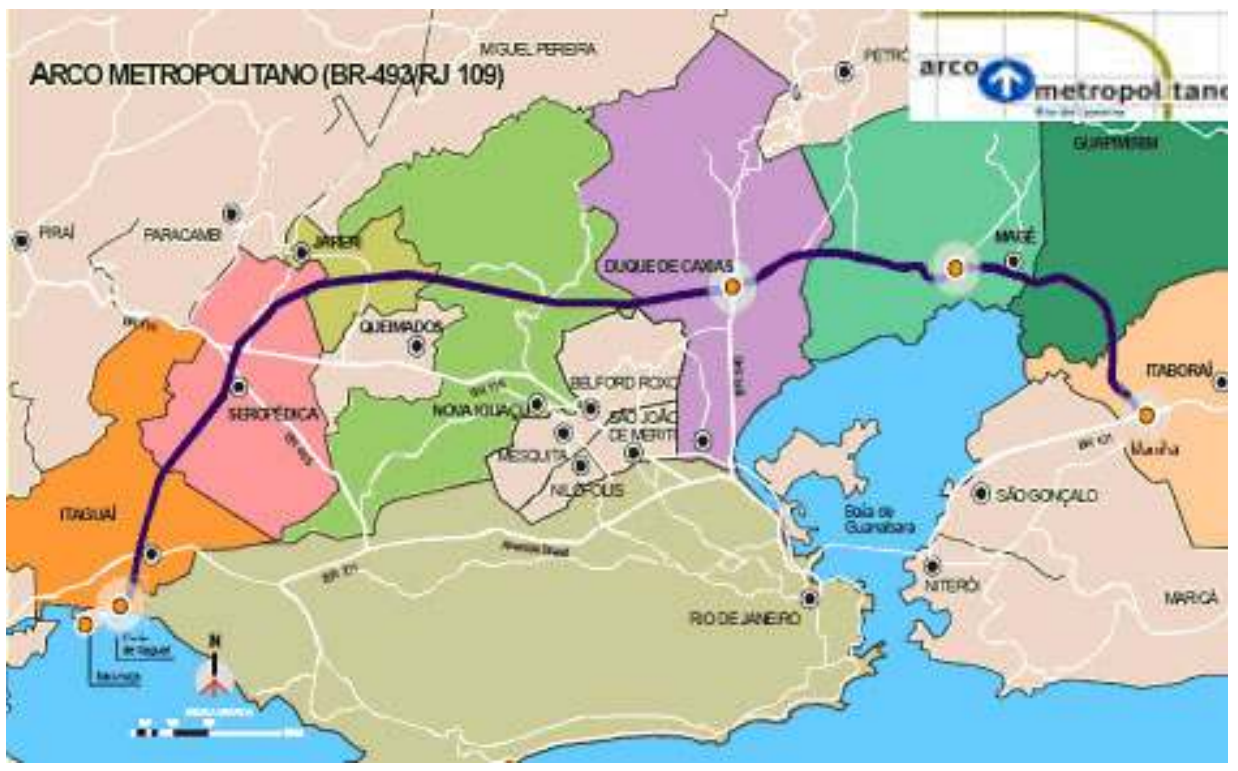

Fonte: http://www.obras.rj.gov.br/boletins/Boletim\%20Maio.pdf

2 O Arco Metropolitano integra um conjunto de obras do Programa de Aceleração do Crescimento (PAC), alinhadas também ao projeto da Iniciativa de Integração Regional Sul ${ }^{1}$ (IIRSA). Trata-se de propostas de integração regional em diferentes escalas, que compreendem tanto a dinamização do mercado internacional, nacional quanto a formação de eixos de desenvolvimento econômico das áreas adjacentes do Arco Metropolitano, integradas à política estatal "novodesenvolvimentista", que foi colocada em prática nos Governos Lula (2003-2010) e Dilma (2011-2014). o projeto do Arco remete ao ano de 1974, quando foram traçadas as linhas de seu objetivo original: a construção de um anel rodoviário, com a redefinição da rodovia RJ-109. O projeto não foi levado à frente e somente foi retomado em 2007, passando a ser incluído como uma das obras infraestruturais do PAC.

O Arco representa um projeto complexo na política nacional e estadual, não só de escoamento da produção, e sim como ação que agrega um conjunto de iniciativas multiescalares. Ele é um dos projetos de integração nacional, criados para superar os chamados gargalos infraestruturais que marcam o território brasileiro, por meio do PAC, o principal projeto do segundo governo Lula (2007-2010), que visava a uma intervenção direta do estado na economia a partir de uma série de obras infraestruturais e de urbanização por todo o território.

Em uma outra escala, a estadual, significou um projeto de atração de investimentos e formação de um eixo de desenvolvimento para o estado, que agrega não mais o escoamento, mas todo um mercado logístico-industrial para o espaço metropolitano fluminense, abrindo novas fronteiras mercantis e de serviço. E, por extensão, também teve significação para as prefeituras cujos territórios municipais são cortados pelo Arco e estão em sua área de influência, que receberam investimentos e atraíram uma série de obras que fomentaram o mercado de trabalho local.

O histórico da implementação do Arco expressa não apenas um projeto de intervenção técnica para circulação mercantil. Consiste em uma nova lógica de acumulação que marca 
o atual metabolismo do capital, que compreende também o espaço como uma mercadoria, ou seja, a produção do espaço do Arco Metropolitano e de seu entorno é tomada como mercadoria.

Não se pode deixar de salientar que ele surge do movimento promovido pelo Estado a partir de políticas infraestruturais para fomento econômico através da superação dos gargalos infraestruturais. Ao mesmo tempo, ele também é uma paisagem da crise que assola o estado do Rio de Janeiro, como uma das expressões no imaginário social da crise.

7 É preciso compreendê-lo como um binômio de acumulação e crise, no que tange à compreensão sobre o que é desenvolvimento e o que é a proposta do novo desenvolvimentismo brasileiro. Nesse sentido, o objetivo deste trabalho é analisar o Arco Metropolitano do Rio de Janeiro não somente na lógica de circulação de valor do custo da movimentação da mercadoria, mas também em outras escalas da produção do espaço e dos conjuntos de intencionalidades e representações do desenvolvimento e da modernidade do mundo capitalista global, nacional, regional e local, como expressão da modernização-desenvolvimento traduzida através do Programa de Aceleração do Crescimento, o PAC, para fomento da acumulação capitalista.

\section{O Arco no contexto do Novo Desenvolvimentismo}

9 O conjunto de obras promovidas pelo Programa de Aceleração do Crescimento tem por objetivo oferecer condições para o processo de acumulação e reproduz o modelo ocidentalização-modernização-capitalismo através da agenda econômica do novo desenvolvimentismo. Suas premissas não estão limitadas ao crescimento econômico, e sim à equidade social, porém dentro da ordem do sistema mundial do ocidente capitalista. A partir desse conjunto se impõe um movimento de modernização do território nacional com obras de megaprojetos infraestruturais que fomentaram o mercado consumidor interno, gerando empregos associados a políticas de valorização salarial.

10 Não podemos deixar de salientar que o novo desenvolvimentismo apresenta diferenças significativas das políticas do desenvolvimentismo dos anos 1950, 1960 e 1970, mantendo, no entanto, o princípio da intervenção estatal como meio de promoção do crescimento econômico. É preciso compreender que os primórdios do desenvolvimentismo brasileiro ocorreram nas primeiras décadas do século $\mathrm{XX}$, com a Era Vargas, mas apenas se consolidaram, efetivamente, de forma mais estruturada, na década de 1950 com o Plano de Metas de JK, que atravessou momentos de variações nos anos 1960 e 1970, especificamente no período da ditadura militar. Já nos anos 1980 sofreu sua mais profunda crise político-econômica.

11 Katz (2016) aponta que essas contínuas instabilidades políticas que levaram à descontinuidade das políticas desenvolvimentistas produziram dificuldades para elaborar avaliações sobre o modelo econômico. Esse mesmo autor, ao tentar montar um panorama histórico sobre o desenvolvimentismo, observa que o principal enfoque do que ele chama de desenvolvimentismo tradicional visava superar as problemáticas infraestruturais que poderiam possibilitar o desenvolvimento industrial nacional e levar à superação do modelo econômico de base agroexportadora.

12 A racionalidade desenvolvimentista emerge a partir da crise do modelo agroexportador, que culminou com a ascensão de Vargas ao poder nos anos 1930, quando houve a 
necessidade de construir alternativas à crise econômica de 1929, e isso em uma sociedade de profunda desigualdade social como a brasileira. A estratégia de saída dessa conjuntura foi colocar o Estado como protagonista para a promoção do desenvolvimento nacional, o centro da concepção do "planejamento e execução da política econômica, fundada no desenvolvimento da indústria e no fornecimento do mercado interno, com vistas a implantar um projeto nacional na direção da superação dos problemas econômicos e sociais, nos marcos do sistema capitalista" (ROTTA e REIS, 2017, p. 937).

13 Anos mais tarde, especialmente a partir da década de 1950, com a consolidação de bases industriais e as regulamentações da relação trabalho e capital da Era Vargas, o Plano de Metas e o conjunto de medidas adotadas pelo governo JK, essa política tem seu período áureo. Foram abertas possibilidades, através do Estado, para um novo arranjo de acumulação capitalista no território brasileiro, que se manteve de maneira oscilante nas décadas de 1960 e 1970 pelo regime militar. Na década de 1980, com a crise econômica e social do ideário desenvolvimentista, ocorre a entrada do modelo econômico neoliberal no Brasil, que abandona totalmente o projeto de industrialização nacional, cuja radicalização se dá nos anos 1990 .

14 A crise dos anos 1980 é a crise do desenvolvimentismo. Os prolongados anos de políticas desenvolvimentistas executadas através de endividamentos do Estado para promoção das obras infraestruturais e financiamento industrial provocaram uma crise financeira dos Estados nacionais. Diferentemente da época da crise de 1930, que atravessou os governos populistas de Peron e Vargas, respectivamente na Argentina e no Brasil, esses países, nos anos 1980, viviam um processo de reabertura política dos regimes militares com uma transição para o período democrático dentro de uma conjuntura de explosões de suas dívidas externas. Os Estados nacionais foram obrigados a implantar medidas de austeridades em suas economias para a manutenção do pagamento aos seus credores. Nesse sentido, os anos 1980 ficaram conhecidos como década perdida, por ter sido marcada por altos índices de desemprego, baixo crescimento econômico e altas taxas de inflação.

15 Harvey (2014) chama esse momento de virada neoliberal. Foi um período marcado por fortes processos de desregulamentação do papel do Estado na economia no mundo todo, em que as metas de promoção se afinavam com um conjunto de reformas estruturais e privatizações. Ele analisa esse momento a partir de uma série de medidas tomadas pelos países desenvolvidos, especificamente pelos Estados Unidos e pela Inglaterra, nos governos de Ronald Reagan e Margaret Thatcher, em que se começa a ter como base o receituário neoliberal, cujas implicações demandavam a saída do Estado da economia, uma série de políticas de privatizações e flexibilizações das relações trabalhistas etc.

16 No caso latino-americano, Zibechi e Machado (2017) afirmam que a implantação do modelo neoliberal se deu em dois momentos: o primeiro, em que foram aplicadas as "reformas de primeira geração" com critérios prioritários para o ajuste anti-inflacionário, cortes de gastos públicos e aumento de juros; e o segundo, na década de 1990, com as "reformas de segunda geração", que implicaram aberturas comerciais, privatizações e flexibilização do mercado de trabalho, cujo ponto chave ficou conhecido como Consenso de Washington, o encontro, em 1989, na capital americana, em que os países latinoamericanos se comprometeram a estruturar seus Estados de maneira equilibrada em termos fiscais e financeiros para promover um ajuste macroeconômico.

17 Tais medidas foram incorporadas como parte do receituário imposto pelo FMI, Banco Mundial e Tesouro Americano como forma de liberação de empréstimos, com garantia de 
seus pagamentos e de seus juros. Os organismos internacionais ditaram as políticas macroeconômicas - e ainda ditam - dos Estados nacionais com uma agenda de austeridade e arrojo salarial. É importante analisar que o Banco Mundial assumiu o papel, nesse período, de determinar uma série de políticas sociais de melhoria de renda e inserção da população no mercado consumidor. Essas ações serão desenvolvidas durante os anos 1990, adquirindo relevância nos governos latino-americanos nos anos 2000.

No Brasil, os Governos Collor (1990-1992) e Fernando Henrique Cardoso (1995-2002) tiveram esse papel de implantação do ideário neoliberal na estrutura do Estado brasileiro, impondo uma série de privatizações às empresas estatais de caráter estratégico para a economia nacional. Esse fluxo é "quebrado" com a eleição de Lula em 2002, embora ele tivesse mantido, em seu primeiro mandato, as matrizes da política econômica do governo FHC, sob a ordem neoliberal. Porém, muitos analistas, como o economista João Sicsi, o sociólogo Emir Sader e outros intelectuais, veem nos períodos dos governos petistas uma ruptura com o receituário neoliberal, que ficou denominado como período dos Governos Progressistas pós-neoliberais.

Essa ruptura representa, de certa forma, uma derrota política do movimento neoliberal e assume um caráter simbólico em termos de luta política. Não podemos esquecer que, no atual cenário global, o neoliberalismo não se insere somente como ideário no campo econômico, mas como forma política e social que se expressa nos agentes estatais e globais em uma nova razão do mundo (DARDOT e LAVAL, 2015). Ele passa a ser uma racionalidade social, que se constitui como modo de organização da sociedade capitalista contemporânea, e persiste na forma de organizador das concepções e práticas dos capitalistas. 0 neoliberalismo tem por característica:

o fato de alterar radicalmente o modo de exercício do poder governamental, assim como as referências doutrinais no contexto de uma mudança das regras de funcionamento do capitalismo. Revelam uma subordinação a certo tipo de racionalidade política e social articulada à globalização e à financeirização do capitalismo (DARDOT e LAVAL, 2015, p. 190).

Nesse sentido, o neoliberalismo se tornou hegemônico como discurso social e foi incorporado enquanto modo de pensamento e maneira cotidiana de as pessoas interpretarem, viverem e compreenderem o mundo e as relações sociais e institucionais (HARVEY, 2014). Não se trata, simplesmente, de uma retirada do Estado de cena; trata-se de um novo reengajamento político ideológico social, no qual o Estado ganha novos contornos estruturais e objetivos de agente ordenador social. Isso significa dizer que o neoliberalismo se reconfigura em novos arranjos institucionais em sua crise estrutural, particularmente no início da década dos anos 2000.

21 Castelo (2013) analisa que a crise estrutural do sistema neoliberal, no início dos anos 2000, abriu caminho para um novo formato do sistema, em que a questão social ganha centralidade a partir da atuação do Estado, com uma ingerência singular, no sentido de: regulação estatal nas atividades econômicas privadas, parcerias público-privadas no investimento econômico e políticas sociais de perfil focalista, filantrópico e assistencialista para o combate às principais expressões da questão social. $\mathrm{O}$ autor denomina a transformação da ideologia neoliberal em social-liberalismo, cuja centralidade está na concepção de uma equidade social para maior equilíbrio nas relações de mercado.

Essa variação do neoliberalismo no Brasil foi gestado no segundo governo FHC (1999-2002), após um choque de políticas de privatizações e ajustes fiscais encabeçadas 
em seu primeiro mandato. A sua forma mais expressiva, segundo Castelo (2013), teve lugar durante os governos do PT, Lula (2003-2010) e Dilma (2011-2015), que assumiram como forte centralidade a questão social como meio de alavanca do desenvolvimento nacional.

Para tanto, a primeira eleição de Lula, em 2002, mostrou o alinhamento dos governos petistas com a perspectiva do social-liberalismo. Forte exemplo encontra-se especialmente na Carta ao Povo Brasileiro, documento elaborado como plano de governo do primeiro governo Lula, cuja essência indicava a manutenção do regime de acumulação financeira. A Carta ao Povo Brasileiro acenava ao mercado a manutenção dos alicerces da política econômica neoliberal do Consenso de Washington, que havia sido implantada no país durante a era $\mathrm{FHC}$, assumindo, ao mesmo tempo, um viés de preocupação com o combate à pobreza extrema.

No final do primeiro governo Lula, já se constata um certo movimento de mudança de um perfil mais ortodoxo da gestão macroeconômica em direção a ações heterodoxas de intervenção direta do Estado na economia, cujo ponto central é o Programa de Aceleração do Crescimento, o PAC. Nesse momento, há o início da implementação de um conjunto de medidas sob a égide do que foi denominado novo desenvolvimentismo. $O$ enfoque passa a ser contrário à teoria neoliberal do "Estado mínimo" e a todos os diversos discursos sobre a "retirada do Estado". Essa retórica, de fato, esconde a continuidade da expansão de um organismo que acentua sua incidência junto à expansão da acumulação. $O$ que se modifica com o passar do tempo são as funções que o Estado exerce para privilegiar certas atividades em detrimento de outras.

Uma guinada é dada no horizonte das bases históricas do desenvolvimentismo tradicional no Brasil. o Estado passa a ser indutor/catalisador do crescimento econômico, sem que seja excluída, no entanto, a característica agroexportadora da economia brasileira, que utiliza o agronegócio como meio para financiar o processo de reindustrialização nacional, já que é o principal setor econômico do país, contribuindo em torno de $30 \%$ no PIB nacional, segundo dados do IBGE, e consolidando-se como um dos mais avançados e modernos setores da economia brasileira.

26 A retomada com novos parâmetros estruturais do papel do Estado como agente indutor do crescimento econômico detém diferenças conjunturais e estruturais do desenvolvimentismo proposto por Raul Prebisch, Albert Hischman, Celso Furtado entre outros, que formavam a Comissão Econômica para a América Latina e o Caribe, a CEPAL. Esse grupo de pensadores visava promover o desenvolvimento econômico dos países subdesenvolvidos ou periféricos, que não haviam realizado sua revolução industrial e capitalista, de uma forma alternativa ao modelo liberal. o novo desenvolvimentismo, que deu base aos governos do PT, formula-se em uma matriz de equilíbrio Estado-Cêntrica e Mercado-Cêntrica, cuja presença estatal não deve obstruir o investimento privado, e a gestão pública tem que reproduzir a eficiência do gerenciamento do setor privado (KARTZ, 2016).

27 Esse movimento do Estado representa, segundo Bresser-Pereira (2016), a construção de uma estratégia nacional de desenvolvimento. $O$ Estado tem a função de garantir que as empresas possam investir e aumentar continuamente a produtividade, produzindo condições gerais para que haja a acumulação de capitais.

28 O novo desenvolvimentismo, especificamente nos governos Lula (2003-2010), se configurou em equilíbrio, que ora se aproximava, ora se afastava da perspectiva 
neoliberal, associando-se com a perspectiva dos modelos Keynesianos. Segundo Jardim e Silva (2015):

o Estado coordenou os mercados durante o governo Lula, produzindo bens e serviços por meio de empresas estatais e parcerias com o capital privado, estabelecendo projetos com base nos recursos oriundos do mercado financeiro especialmente dos fundos de pensão e do BNDES, via emissão de títulos públicos e por meio de investimentos diretos nas empresas -, assim como coordenou certa regulamentação de mercado (p. 54).

Esse equilíbrio entre as forças do mercado financeiro e o setor industrial no período Lula (e durante o primeiro governo Dilma) ${ }^{2}$ teve no PAC a sintetização dessas medidas e intervenções estatais, como o Plano de Metas do período JK, voltadas para o processo de modernização e dinamização do capitalismo brasileiro.

O Programa de Aceleração do Crescimento foi colocado em prática em janeiro de 2007, como carro chefe do segundo mandato do governo Lula. Tratou-se de um programa de centralização do planejamento e acompanhamento da introdução de infraestrutura para facilitar e promover o aumento da produtividade e a superação dos desequilíbrios regionais e sociais, envolvendo ações conjuntas com a iniciativa privada, o que ficou conhecido como PPPs (Parcerias Público-Privadas).

31 A estruturação do PAC se deu a partir de uma série de medidas legislativas, administrativas e políticas de investimentos, implicando desonerações de determinados setores estratégicos, notadamente centralizadas no setor de logística, energia e infraestrutura. Foi retomada uma série de projetos infraestruturais desenhados no período da ditadura militar para os Planos Nacionais de Desenvolvimento (I PND, 1969-1974, II PND, 1974-1979, e III PND, 1979-1985), obviamente reformulados e atualizados com as demandas do capitalismo contemporâneo, fora os projetos elaborados durante os anos 1990 e as parcerias com o Banco Mundial.

O PAC é um sistema complexo de execução. Toda a sua gestão em termos de obras é feita a partir de três esferas: municipal, estadual e federal. Tanto o município quanto o estado têm que submeter projetos de obras à análise do comitê gestor, para serem financiadas pelo programa. Os recursos de financiamento do PAC vinham em parte do Tesouro Nacional (mediada pelo BNDES ${ }^{3}$ ), da parceira com fundos de pensão, do Fundo de Amparo ao Trabalhador (FAT) e de Parceiras Público Privadas (PPPs), que

foram criadas através da lei n. 11.079 de 2004, como alternativa do governo à falta de recursos para investimentos em obras de infraestrutura, buscando, dessa maneira, parceiros privados nos investimentos, tendo como principal financiador o BNDES (via recursos do Tesouro) e a participação relevante dos fundos de pensão nas PPPs, inclusive na composição acionária das Sociedades de Propósito Específico (SPE) (JARDIM e SILVA, 2015, p. 59).

33 As ações do governo têm o sentido de promover a atração de investimentos privados a partir dos investimentos públicos. Essa atração promove, através das PPPs, a transferência para o capital da gestão e comercialização de serviços básicos das sociedades como saneamento, habitação, transporte (estradas, metrô etc.). Dentro dessa estrutura, a relação entre Estado e mercado se estabelece de forma que ao primeiro caiba o papel de promotor e ao segundo a gestão. No entanto, verifica-se que há uma desigualdade de compartilhamento de riscos dos investimentos. O prejuízo não é socializado entre ambos; é, na maioria das vezes, acarretado pelo Estado. Trata-se, na verdade, de uma forma alternativa ao modelo de privatização de setores estratégicos, abrindo-se para a gestão privada por concessão. 
34 Essa articulação de diálogo entre Estado e mercado durante os governos do PT se configurou como um meio de formação de um projeto nacional de desenvolvimento, que se deu, porém, de modo ameno e conformista. Ocorreram tensões, contradições, ambiguidades e relações de poder próprias desse momento. Pode-se mesmo dizer que havia um acordo de convivência entre as elites e as bases sociais fundadoras do Partido dos Trabalhadores, que conseguiu, a partir das alianças mais próximas com setores conservadores, formar um governo de coalisão durante o segundo governo Lula e deu bases para a eleição de Dilma em seguida, que, em seus governos, não conseguiu o mesmo diálogo com o mercado tanto quanto o seu antecessor, como analisaremos mais à frente.

A questão social sempre foi o ponto central das gestões petistas, por isso o debate sobre o novo desenvolvimentismo não se limita à questão da modernização técnico-científicoinformacional nacional. Um conjunto de ações foi implementado para ampliar as políticas de desenvolvimento regional e a integração dos mercados nacionais, direcionadas para o combate à fome e erradicação da miséria extrema no país, com políticas de renda mínima e geração de emprego.

O novo desenvolvimentismo brasileiro também transpassa as fronteiras e está atrelada a uma série de intervenções no âmbito do cone sul, especialmente no continente sulamericano, área de atuação geopolítica privilegiada pelos governos Lula, com medidas de integração e fortalecimento político do bloco continental, retomada do Mercosul, construção da UNASUL, elaboração de tratados e acordos infraestruturais na região, que integrassem economicamente a sociedade.

Quando analisamos todo esse contexto político, social e econômico em que se estabelece o projeto novodesenvolvimentista, podemos compreender o Arco Metropolitano como uma das peças técnicas da política de integração nacional desenvolvida no período dos governos petistas. Como indicamos em seções anteriores, ele é um projeto dos anos 1970, que somente teve sua execução a partir do ano 2007, como parte das políticas de desenvolvimento elaboradas no segundo governo Lula, inserindo-se dentro do PAC na linha dos projetos estruturais de transporte.

O PAC Transportes foi um programa voltado para o investimento na infraestrutura rodoviária, ferroviária e hidroviária brasileira. A modernização e expansão do sistema de transporte e logística objetivavam acabar com um dos principais "gargalos" infraestruturais da rede viária brasileira, que tem como centralidade o modelo rodoviário implementado no período do Plano de Metas. O objetivo de um projeto tão complexo como o PAC Transportes foi de promover uma redução do tempo e do custo de deslocamento e armazenamento dos produtos brasileiros.

Nesse sentido, o Plano Nacional de Logística e Transporte, lançado em 2006, depois de vinte anos sem planejamento de infraestruturas, foi a base dessa vertente do PAC, que foi elaborado em parceria do Ministério dos Transportes (MT) com o Ministério da Defesa, por meio do Centro de Excelência em Engenharia de Transportes (CETRAN). Teve como caráter indicativo as obras que eram prioritárias até a década seguinte e trouxe como destaque as obras de infraestrutura principalmente nas regiões Sudeste e Centro-Oeste, o principal centro consumidor e industrial e a principal região produtora de soja, um dos produtos de maior relevância econômica do agronegócio brasileiro. Todo um planejamento foi montado para dinamizar a logística, o transporte e a energia de maneira a produzir bases para um processo de reindustrialização brasileira. 
40 As ordens dos investimentos do PAC alcançaram em torno de 503,9 bilhões de reais nos quatro anos que se seguiram. A economia brasileira nesse período cresceu em média 4,6\% ao ano, apesar do contexto de crise internacional dos anos 2008 e 2009. Esse crescimento não foi somente viabilizado pelas ações do PAC. Traduziram-se em uma série de ações que vão desde a participação ativa da Petrobrás em investimento em infraestrutura na produção petrolífera nacional, na parte de refino e exploração, quanto nas políticas de conteúdo local.

41 Todo esse ambiente de crescimento econômico foi o suficiente para que Lula acumulasse forças eleitorais para eleger sua sucessora, a chefe de seu governo e principal gestora do PAC, Dilma Rousseff, no ano 2010. No entanto, a eleição de Dilma não só significou a primeira mulher eleita para a presidência da República. Expressou também a consolidação de um fenômeno político chamado lulismo:

o lulismo, que emerge junto com o realinhamento, é, do meu ponto de vista, o encontro de uma liderança, a de Lula, com uma fração de classe, o subproletariado, por meio do programa cujos pontos principais foram delineados entre 2003 e 2005: combater a pobreza, sobretudo onde ela é mais excruciante tanto social quanto regionalmente, por meio da atividade do mercado interno, melhorando o padrão de consumo da metade mais pobre da sociedade, que se concentra no Norte e Nordeste do país, sem confrontar os interesses do capital. Ao mesmo tempo, também decorre do realinhamento o antilulismo que se concentra no PSDB e afasta a classe média de Lula e do PT (SINGER, 2012, p. 15-16).

O lulismo se consolida como uma das formas políticas brasileiras na eleição de Dilma (2010 e 2014), caracterizando-se por um realinhamento das forças históricas de formação do PT, de setores populares e da classe média, para setores subproletarizados, que se identificaram com o projeto, ao qual se refere Lula como "colocar o pobre no orçamento". Configurou-se como um pacto conservador dentro da coalisão governamental para dar condições de continuidade das políticas desenvolvimentistas iniciadas por Lula, alinhando-se com diferentes setores sociais dos partidos brasileiros, da esquerda, centro e direita, um bloco de composição complexo, que teve no PMDB, Partido do Movimento Democrático do Brasil, o principal aliado, na figura do vice-presidente Michel Temer.

O Governo Dilma foi um produto do lulismo e um aprofundamento da política novodesenvolvimentista, a partir da "nova matriz econômica" dirigida pelo ministro da fazenda Guido Mantega. Esse aprofundamento tinha como foco central combater a crise internacional de 2009 e evitar que seus efeitos chegassem ao Brasil. Todo o enfoque se deu na ampliação do Estado na economia, com o objetivo claro de aprofundar de maneira acelerada o lulismo.

O Programa de Aceleração do Crescimento foi relançado no novo governo petista e nesse momento de tentativa de consolidação do lulismo. A ele foi dado o nome de PAC 2. Houve um aumento orçamentário significativo devido ao superávit primário dos anos anteriores e à necessidade de acelerar as mudanças iniciadas nos governos Lula. O PAC 2 entra em ação. Ele é o aprimoramento do PAC com mais recursos e aprofundamentos de articulações de estado e municípios com o governo federal. Em termos orçamentários, o programa atingiu a casa dos 850 bilhões de reais em obras de mobilidade urbana, saneamento básico, energia, eletrificação, infraestrutura escolar etc.

Entretanto, Dilma constrói sua política novodesenvolvimentista, enfrentando justamente um dos setores com os quais Lula manteve um certo diálogo, o mercado. Medidas como redução do custo de energia, baixos juros dos bancos estatais, desonerações para grandes setores empresarias, ampliação do crédito no BNDES entre outras tantas entraram em 
choque com os setores mais ortodoxos brasileiros e sofreram até mesmo críticas de economistas heterodoxos brasileiros. Fagnani (2017) analisa que o primeiro mandato de Dilma foi o recrudescimento das tensões com o mercado. Para ele,

Do ponto de vista estritamente econômico, esse acirramento decorreu da desaceleração do crescimento, por conta dos desdobramentos da crise financeira internacional e de erros na condução das políticas domésticas. Destaca-se, aqui, dentre tantos outros pontos, o reforço da política de isenções fiscais que contribuiu para piorar as contas públicas e as contas da Seguridade Social.

Do ponto de vista político, o acirramento dessas tensões intensificou-se com a proximidade das eleições de 2014, quando a oposição aprofundou a campanha ideológica contra o suposto programa intervencionista da "esquerda", agora com o propósito de apresentar um Brasil em "crise econômica terminal" (p. 7).

Durante a campanha de reeleição de Dilma em 2014, acirrou-se o debate entre, por um lado, o papel do Estado na economia e o intervencionismo do novo desenvolvimentismo, e, por outro, a retomada do Estado mínimo e de austeridade das políticas do neoliberalismo mais tradicional. Essas foram premissas que marcaram o início de uma crise política, econômica e social brasileira, desde então.

A crise institucional atingiu diferentes escalas da política nacional, produzindo rupturas e dubiedades nas alianças do pacto lulista. 0 estado do Rio de Janeiro foi, talvez, a grande expressão dessa crise, quando os segmentos políticos tradicionais tiveram apoio do lulismo durante o segundo governo Lula e o primeiro governo Dilma. Foi o caso da aliança com o PMDB fluminense, na figura do ex-governador Sérgio Cabral Filho, eleito em $2006 \mathrm{e}$ reeleito em 2010. Foram vultosos os investimentos do PAC no estado e os investimentos estratégicos que alavancaram a economia estadual nesse período. A cidade do Rio de Janeiro era "a cereja do bolo", a capital que mais recebeu eventos globais como a Jornada Mundial da Juventude, os Jogos Olímpicos Militares, a final da Copa do Mundo de 2014, as Olimpíadas de 2016, um dos principais eventos do período de aliança do governo federal petista com a plutocracia estadual peemedebista fluminense/carioca.

A ruptura e dubiedade junto ao pacto no Rio de Janeiro se configura através da aproximação do PMDB fluminense com o PSDB nacional, apoiando de um lado o candidato à presidência em 2014, Aécio Neves, e, de outro, também nesse mesmo ano, a reeleição de Dilma Rousseff. O vice-governador e candidato à época ao governo do estado, Luiz Fernando Pezão, flutuava nessa polarização política que marcava a campanha eleitoral.

Foi crucial o papel do Arco Metropolitano como principal obra inaugurada nesse ano no estado. Pezão usou a inauguração do Arco como propaganda eleitoral e difundiu a ideia de um novo momento do desenvolvimento econômico fluminense. Em seu novo governo, Dilma promoveu um movimento político de diálogo com o mercado, indicando um nome de forte inserção dentro do mundo financeiro para o Ministério da Fazenda, Joaquim Levy, que se propunha a ser o chefe para a implementação de medidas de austeridade, o ajuste fiscal, indo na contramão do que havia proposto na campanha eleitoral, a luta contra o receituário neoliberal.

\section{O Arco e a Economia do estado do Rio de Janeiro}

Para a economia estadual, o Arco é um eixo de desenvolvimento do espaço metropolitano que abre uma nova carteira de possibilidades de crescimento econômico. Está delimitada dentro desse projeto uma divisão territorial do trabalho, que, ao mesmo tempo, expande 
um mercado de terras nessa região, através de seus "espaços vazios", "fomentando" as economias dos municípios cortados pelo Arco. Para tanto, é preciso pensar o estado e suas dinâmicas econômicas e regionais frente aos processos descritos nas unidades acima e sua contextualização na atual conjuntura em que vive a população fluminense.

O estado do Rio de Janeiro tem suas particularidades com relação às questões territoriais que o marcam até hoje como, por exemplo, o distanciamento social do interior e da capital, problema que se constituiu desde a fusão do estado da Guanabara com o estado do Rio e o processo de construção de uma identidade fluminense. Outra questão que está associada a esse fato é a forte centralidade da metrópole carioca. Grande parte da população do estado está localizada na região metropolitana. O Rio de Janeiro é o estado com maior grau de urbanização do Brasil.

Nosso interesse, neste momento, é debater sobre as questões de economia e indústria do estado e suas transformações nos últimos anos, bem como destacar os investimentos do PAC na dinâmica territorial fluminense. Nossa preocupação se dirige à dinâmica regional estadual, e não somente à escala da cidade do Rio de Janeiro, até mesmo porque nosso foco está centrado no espaço metropolitano. Porém, é inegável a centralidade regional e nacional da capital, que foi revigorada com os investimentos do PAC e das obras para as Olimpíadas e a Copa do Mundo. A Cidade Maravilhosa retorna, assim, a seus momentos áureos de capital nacional como cartão postal do Brasil.

O estado, via políticas do PAC, obteve fortes investimentos em sua base logística e na indústria petrolífera, especialmente com a descoberta do Pré-Sal na bacia de Campos, a construção do submarino nuclear em Itaguaí, a volta de investimentos na usina nuclear de Angra dos Reis e em portos como o do Açu e Itaguaí. Todos esses processos representam novas fronteiras de acumulação do capital no estado, indo no sentido do interior estadual em direção à franja metropolitana nas vertentes leste e oeste, como bem exemplificam os investimentos do COMPERJ e os condomínios logístico-industriais para o escoamento para o Porto de Itaguaí. A imagem 2 representa os investimentos do PAC entre os anos 2011 e 2014 no estado do Rio de Janeiro: 




Fonte: $10^{\circ}$ Balanço PAC2 Rio de Janeiro, março-junho de 2014.

54 O PAC no Rio de Janeiro atuou em uma diversidade de investimentos que abrangia desde mobilidade urbana a saneamento básico para as comunidades carentes da capital. São exemplos o PAC Favelas, o PAC Mobilidade Urbana, o projeto de investimento em energia, entre outras tantas iniciativas que figuravam no cenário projetado para o segundo período de gestão de Sérgio Cabral Filho (2011-2014) e situado pelos economistas neoliberais fluminenses no slogan "Rio- Hora da Virada", fazendo alusão à virada da crise societária e econômica que havia assolado o estado por vários anos. Com um receituário neoliberal, três instituições construíram esse projeto econômico-social em nível estadual: o Instituto Millenium, a Federação das Indústrias do estado do Rio de Janeiro (FIRJAN) e o Banco Mundial, que atuam não só em projetos infraestruturais, mas em todas as instâncias da gestão e elaboração de projetos sociais e essenciais como saúde, educação, saneamento básico, entre outros.

55 A logística e o extrativismo mineral, especialmente no Noroeste e Norte fluminenses, com o mineroduto e a exploração petrolífera, entram dentro desses conjuntos de planos como uma das bases essenciais do que se colocaria nesse momento para a economia fluminense. Para Egler et al (2015), era preciso propor uma base não só para os projetos nacionais de territorialização no espaço fluminense, mas também para um projeto de desenvolvimento regional para o estado, que trouxesse coesão entre as regiões do estado, articulando a rede viária em suas diferentes escalas territoriais.

56 Segundo o documento da FIRJAN “Decisão Rio 2014-2016", as estimativas de investimentos no estado eram de 235,6 bilhões de reais nesse período. $60,7 \%$ deste valor estavam relacionados a investimentos no setor de petróleo e gás, e outros $16,1 \%$ para o setor de infraestrutura, cujos principais projetos estavam voltados à mobilidade urbana 
da cidade do Rio de Janeiro, de que são exemplos o BRT, o VLT, o Metrô e o projeto central para o desenvolvimento da região metropolitana, o Arco Metropolitano do Rio de Janeiro.

Todos esses projetos estão articulados no documento intitulado "Visões para o futuro", lançado em 2012, da FIRJAN, que descrevia uma série de propostas para o desenvolvimento econômico do estado, com proposição de vigência de um período de 5 a 15 anos, contando com investimentos por parte do Estado e da iniciativa privada, reiteradas em seu plano quinquenal no final de 2014. Nesse documento, destaca-se o papel de importância estratégica do Arco Metropolitano para o desenvolvimento econômico do estado, pelo fato de integrar toda a região metropolitana, complementar o acesso rodoviário com o Porto de Itaguaí e aproximar o município de Duque de Caxias - onde está instalada a Refinaria Duque de Caxias (REDUC) - ao Leste Fluminense, onde está sendo construído o complexo petroquímico COMPERJ, no município de Itaboraí.

Com o Arco, poderia ser produzida uma série de benefícios logísticos que atrairiam um grande número de habitantes e empresas para o seu entorno (FIRJAN, 2014). A análise da Federação das Indústrias do Estado do Rio de Janeiro toma como base os "espaços vazios" nas adjacências do Arco. $O$ seu entorno se tornou um espaço de atração para inúmeras iniciativas e investimentos nos municípios sobre os quais ele tenha influência territorial. Toda essa discussão e praticidade começam efetivamente em 2011 e 2012, com os avanços da execução das obras do Arco.

Somente o investimento na obra do Arco em suas diferentes etapas de construção causou um impacto positivo na economia fluminense, já que houve aumento do emprego no setor de construção civil e metalurgia, fora as ditas possibilidades de geração de emprego com as empresas que se instalassem nos seus arredores ${ }^{4}$. Alguns jornais anunciavam que o eixo Itaguaí-Itaboraí poderia vir a gerar em torno de 800 mil empregos para a região metropolitana.

60 Isso foi um dos aspectos que marcaram o imaginário de desenvolvimento que o Arco poderia promover à economia fluminense em especial para a região metropolitana. É preciso destacar que o processo de construção encontrou dificuldades em termos ambientais e sociais, que motivaram as paralisações das obras e os replanejamentos sobre ocupação devido a questões envolvendo a fauna e flora e patrimônios arqueológicos que foram encontrados no processo de terraplanagem. Outros fatores relacionados à complexidade da execução da obra estão associados a problemas políticos, casos de corrupção, sobrevalorização da obra etc. Souza (2015) retoma a história dos prolongamentos da obra do Arco da seguinte forma:

Apesar de o Arco ter sido anunciado desde o início de 2007, a cerimônia solene de assinatura de início das obras só ocorreu em maio de 2008, quando foi estabelecido o prazo de inauguração do AMRJ para o final do ano de 2010. Ao longo de sete anos, as obras do AMRJ sofreram atrasos justificados pelos mais diversos motivos. Dentre eles, os que ganharam maior destaque na mídia foram a descoberta de sítios arqueológicos ao longo da rodovia, a descoberta de espécies raras de rã e peixe na Floresta Nacional Mário Xavier (cortada pelo traçado do Arco) e a falta de matériaprima para as obras. A lentidão na desapropriação dos terrenos que seriam utilizados na obra também foi um motivo bastante relevante, segundo as entrevistas realizadas com representantes de entidades relacionadas com a obra do Arco. Entretanto, esta justificativa não ganhou muita repercussão e sempre foi negada pelos representantes do poder público (p. 86).

61 Ao apresentar o panorama acima, Souza (2015) traz a análise do reordenamento territorial produzido pelo Arco dentro do espaço metropolitano fluminense. Dessa 
maneira, um conjunto de agentes se insere nesse espaço, remodelando-o para receber os novos investimentos. Os municípios cortados por ele ou que estão em sua zona de abrangência promovem novos zoneamentos para se adequarem às demandas que apareceriam com a construção do Arco. Esse é um outro debate que emerge em nossa discussão na escala estadual, mas que também precisa ser feito na escala metropolitana e local.

\section{Considerações finais}

O Arco foi um dos principais destaques políticos para o desenvolvimento econômico do estado e propaganda do candidato da situação à época, eleito governador no mesmo ano, Luiz Fernando Pezão, no pleito de 2014. Com a chegada da crise efetivamente em 2015, o estado passa a viver um dos períodos mais drásticos de recessão e falência financeira. A crise se dá a partir da queda dos preços das commodities, uma das bases do PIB brasileiro, uma vez que o petróleo foi um dos produtos mais atingidos pela queda dos preços.

o Arco passou a ganhar destaque não mais como modernidade e desenvolvimento, mas como uma área de alto risco, marcada por assaltos e roubos de cargas e carros, além de outros recorrentes às populações que vivem em suas adjacências. $\mathrm{O}$ abandono em termos de investimentos e manutenção, bem como a falta de segurança transformaram essa via em um navio sem rumo, apesar de algumas tentativas logradas e inúmeros planos ainda não executados para esse eixo.

Com isso, buscamos compreender o Arco Metropolitano em suas diferentes dimensões e escalas de atuação nas transformações espaciais da dinâmica metropolitana fluminense. E observamos o Arco em seus diferentes momentos: como um equipamento técnico que tem como objetivo ser um eixo de integração de rodovias federais, promovendo o deslocamento de mercadorias, pessoas e serviços; como parte de um plano de desenvolvimento nacional conhecido como Programa de Aceleração do Crescimento (PAC).

\section{BIBLIOGRAPHY}

BRASIL. Ministério do Planejamento, Orçamento e Gestão. 10ํㅡㄹalanço PAC2 Rio de Janeiro, junho de 2014.

BRESSER-PEREIRA, Luiz Carlos. Reflexões sobre o Novo Desenvolvimentismo e o Desenvolvimentismo Clássico. REVISTA DE ECONOMIA POLÍTICA (ONLINE), v. 36, p. 237-265, 2016

CASTELO, Rodrigo. O social liberalismo: auge e crise da supremacia burguesa na era neoliberal. - 1.ed.São Paulo: Expressão Popular, 2013.

DARDOT, Pierre; LAVAL, Christian. A nova razão do mundo: ensaios sobre a sociedade neoliberal. 1 ed. São Paulo: Boitempo, 2016. 
EGLER, Claudio Antonio Gonçalves; DOMINGUEZ, Marcos Thimoteo ; REGATO, André Neuschwang . Dinâmica Territorial e a Estruturação Espacial do Estado do Rio de Janeiro. CADERNOS DO DESENVOLVIMENTO FLUMINENSE, v. 8, p. 11-22, 2015.

FAGNANI, Eduardo. O fim do breve ciclo da cidadania social no Brasil (1988-2015).. Texto para Discussão (Campinas), v. 308, p. 1-22, 2017.

HARVEY, David. 17 contradições e o fim do capitalismo -1.ed.- São Paulo: Boitempo, 2016. A produção capitalista do espaço. -2ª .ed.- São Paulo: Annablume, 2005. Espaços de esperança. -2 $2^{\mathrm{a}}$.ed.- São Paulo: Edições Loyola, 2006. . 0 neoliberalismo: história e implicações - 5.ed.- São Paulo: Edições Loyola, 2014.

IANNI, Octavio. A Sociedade Global. Rio de Janeiro: Civilização Brasileira. 1993.

JARDIM, Maria Chaves; SILVA, Márcio Rogério. Programa de aceleração do crescimento (PAC): neodesenvolvimentismo?. 1. ed. S. Paulo: Unesp, selo acadêmico, 2016.

KARTZ, Claudio. Neoliberalismo, neodesenvolvimentismo, socialismo.-1.ed.- São Paulo: Expressão Popular:Perseu Abramo, 2016.

ROTTA, Edemar.; REIS, Carlos Nelson dos. A teoria e a prática do desenvolvimento no Brasil: o estado e as políticas públicas como instrumentos da reprodução do capital. In: VIII Simpósio Iberoamericano em Comércio Internacional, Desenvolvimemento e Integração Regional, 2017, Cerro Largo. Anais do VIII Simpósio Iberoamericano em Comércio Internacional, Desenvolvimento e Integração Regional v. II. Cerro Largo: UFFS, 2017. v. 1. p. 923-938

SILVEIRA, Márcio Rogério; JULIO, A. S. . Os Investimentos em Transportes do Programa de Aceleração do Crescimento (PAC) e o Efeito Multiplicador Brasileiro a partir do Governo Lula da Silva. Revista de Literatura dos Transportes, v. 7, p. 199-224, 2013.

SINGER, André Vitor. Os sentidos do lulismo: reforma gradual e pacto conservador.- 1'ed. - São Paulo: Companhia das Letras, 2012.

SISTEMA FIRJAN. Visões para o futuro: potencialidades para o estado do Rio de Janeiro. Setembro de 2012.

SOUZA, Ticianne Ribeiro de. 0 papel da ideologia na expansão urbana: a questão econômica e os impactos socioambientais do Arco Metropolitano do Rio de Janeiro. 2015. Dissertação (Mestrado em Arquitetura e Urbanismo) - Universidade de São Paulo.

TÂNGERI, Vera Regina; REGO, Andrea Queiroz; MONTEZUMA, Rita de Cássia Martins (Orgs.). 0 Arco Metropolitano do Rio de Janeiro: integração e fragmentação da paisagem metropolitana e dos sistemas de espaços livres de edificação. Rio de Janeiro: PROARQ/FAU, 2012.

ZIBECHI, Raúl. Machado, Décio. Os limites do progressismo: sobre a impossibilidade de mudar o mundo de cima para baixo. .- 1.ed.- Rio de Janeiro: Consequência Editora, 2017.

\section{NOTES}

1. A Iniciativa de Integração da Infraestrutura Regional Sul-Americana, IIRSA, é um projeto multissetorial que pretende desenvolver e integrar as áreas de transporte, energia e telecomunicações da América do Sul.

2. Temos que apontar que esse momento de retomada do investimento público em obras infraestruturais teve como pilar o período conhecido como "Boom das Commodities", marcado 
pelo aumento dos preços de produtos como soja e petróleo e também pela descoberta dos poços de petróleo na Bacia de Campos, o Pré-Sal.

3. Banco Nacional do Desenvolvimento Econômico e Social. Temos que destacar que o BNDES passou a ter atuação diferente da do período FHC, em que o banco ficou como mediador e gestor do processo de privatizações que marcaram esse momento. Nos governos petistas, o BNDES retoma o papel enquanto agente de crescimento econômico, não só financiando, mas atuando como participante dos conselhos empresariais das empresas que investiram na compra de ações, como uma estratégia de direcionar e acompanhar os investimentos. Os bancos públicos assumem papel estratégico na política desenvolvimentista, pelo financiamento dos investimentos da iniciativa privada e dos estados para os mesmos sendo responsáveis.

4. $\mathrm{Na}$ atual conjuntura, não é possível obter dados concretos acerca de quantos empregos foram criados efetivamente após a inauguração do Arco Metropolitano. Há uma série de dificuldades para acessar essas informações, tais como: a falta de pesquisas desse gênero e a crise fiscal que assola o estado, promovendo uma saída de investimentos e a não inserção de novos na escala estadual. Oliveira e Silva (2017) indicam que é preciso chamar atenção para o fato de que, dada a contemporaneidade da obra (instalação e inauguração), não há ainda um conjunto considerável de indicadores oficiais de emprego, renda e atividade econômica que permita auferir os impactos. É importante lembrar que os principais órgãos de pesquisa e divulgação desses dados, no Brasil, trabalham com um atraso de aproximadamente três anos em relação ao ano de divulgação dos resultados e o ano de análise (p.86).

\section{ABSTRACTS}

The Metropolitan Arch integrates a set of works of the Growth Acceleration Program (PAC). These are proposals for regional integration at different scales, which include both the dynamization of the national internal market and the formation of axes of economic development in the adjacent areas of the Metropolitan Arc, linked to the new developmentalist policy, which was put into practice while Lula (2003-2010) and Dilma (2011-2014) were presidents of Brazil. The Arch project refers to 1974, when the lines of its original objective were drawn: the construction of a ring road, with the redefinition of the highway RJ-109. The project was not taken forward and was only resumed in 2007, being included as one of the infrastructure works of the PAC. The Arch represents a complex project in national and state politics, not only of production but as an action that bundles a set of multi-scale initiatives. This paper aims at analyzing the Metropolitan Arch of Rio de Janeiro in its sets of intentionalities, and its representations of the development and modernity in the global, national, regional and local capitalist world as an expression of the modernization and development, translated by the Growth Acceleration Program (PAC) in order to foster capitalist accumulation.

O Arco Metropolitano integra um conjunto de obras do Programa de Aceleração do Crescimento (PAC). Trata-se de propostas de integração regional em diferentes escalas, que compreendem tanto a dinamização do mercado interno nacional quanto a formação de eixos de desenvolvimento econômico das áreas adjacentes do Arco Metropolitano, integradas à política estatal "novodesenvolvimentista", que foi colocada em prática nos Governos Lula (2003-2010) e Dilma (2011-2014). O projeto do Arco remete ao ano de 1974, quando foram traçadas as linhas de seu objetivo original: a construção de um anel rodoviário, com a redefinição da rodovia RJ-109. 0 
projeto não foi levado à frente e somente foi retomado em 2007, passando a ser incluído como uma das obras infraestruturais do PAC. O Arco representa um projeto complexo na política nacional e estadual, não só de escoamento da produção, e sim como ação que agrega um conjunto de iniciativas multiescalares. O objetivo deste trabalho é analisar o Arco Metropolitano do Rio de Janeiro em seus conjuntos de intencionalidades, representações do desenvolvimento e da modernidade do mundo capitalista global, nacional, regional e local, como expressão da modernização-desenvolvimento traduzida através do Programa de Aceleração do Crescimento, o PAC, para fomento da acumulação capitalista.

L'arc métropolitain intègre un ensemble d'œuvres du programme d'accélération de la croissance (PAC). Ce sont des propositions d'intégration régionale à différentes échelles, qui incluent à la fois la dynamisation du marché intérieur national et la formation d'axes de développement économique dans les zones adjacentes de l'Arc métropolitain, intégrées à la politique de l'État "novodeenvolvimentista", qui a été mise en pratique dans Gouvernements Lula (2003-2010) et Dilma (2011-2014). Le projet Arco se réfère à l'année 1974, date à laquelle ont été dessinées les lignes de son objectif initial: la construction d'un boulevard périphérique, avec la redéfinition de l'autoroute RJ-109. Le projet n'a pas été poursuivi et n'a repris qu'en 2007, étant inclus dans les travaux d'infrastructure du PAC. L'Arco représente un projet complexe dans les politiques nationales et des États, non seulement en termes de production, mais également en tant qu'action regroupant un ensemble d'initiatives à plusieurs échelles. L'objectif de ce travail est d'analyser l'Arc métropolitain de Rio de Janeiro dans ses ensembles d'intentionnalités, de représentations du développement et de la modernité du monde capitaliste mondial, national, régional et local en tant qu'expression de la modernisation et du développement traduits à travers le Programme d'accélération de la croissance., le PAC, pour favoriser l'accumulation capitaliste.

El Arco Metropolitano integra un conjunto de obras del Programa de Aceleración del Crecimiento (PAC). Se trata de propuestas de integración regional en diferentes escalas, que comprenden tanto la dinamización del mercado interno nacional como la formación de ejes de desarrollo económico de las áreas adyacentes del Arco Metropolitano, integradas a la política estatal "novodevolvimentista", que se puso en práctica en Gobiernos Lula (2003-2010) y Dilma (2011-2014). El proyecto del Arco remite al año 1974, cuando fueron trazadas las líneas de su objetivo original: la construcción de un anillo carretero, con la redefinición de la carretera RJ-109. El proyecto no fue llevado adelante y sólo se reanudó en 2007, pasando a ser incluido como una de las obras infraestructurales del PAC. El Arco representa un proyecto complejo en la política nacional y estatal, no sólo de salida de la producción, sino como acción que agrega un conjunto de iniciativas multiescalares. El objetivo de este trabajo es analizar el Arco Metropolitano de Río de Janeiro en sus conjuntos de intencionalidades, representaciones del desarrollo y de la modernidad del mundo capitalista global, nacional, regional y local, como expresión de la modernización-desarrollo traducida a través del Programa de Aceleración del Crecimiento , el PAC, para el fomento de la acumulación capitalista.

\section{INDEX}

Palabras claves: Arco Metropolitano, PAC, Nuevo desarrollismo, Río de Janeiro

Keywords: Metropolitan Arch, PAC, New developmentalism, Rio de Janeiro.

Palavras-chave: Arco Metropolitano, PAC, Novo desenvolvimentismo, Rio de Janeiro.

Mots-clés: Arc métropolitain, PAC, Nouveau développementalisme, Rio de Janeiro. 


\section{AUTHOR}

\section{VICTOR TINOCO}

Doutorando PPGEO PUC-RIO, pesquisador do Grupo de estudos urbanos e rurais (URAIS PUC-RIO) e Mestre pelo Programa de Pós-Graduação de Ciências Sociais em Desenvolvimento, Agricultura e Sociedade (CPDA/UFRRJ) Email:victortinoco85@gmail.com.br 